УДК 004.055

DOI $10.21661 / \mathrm{r}-467817$

\title{
A.Г. Проасnэm
}

\section{РАЗРАБОТКА КОРПОРАТИВНОЙ ИНФОРМАЦИОННОЙ СИСТЕМЫ ДЛЯ УПРАВЛЕНИЯ КОНТЕНТОМ ИНТЕРНЕТ-РЕСУРСА ПРЕДПРИЯТИЯ}

Аннотация: существующие программные продукты для управления контентом интернет-ресурса предприятия либо являются трудными для освоения сотрудниками, занимающимися управлением контентом, либо не обеспечивают необходимый уровень безопасности и функциональных возможностей. По мнению автора, необходимо разработать требования к корпоративной информаичонной системе, позволяющей управлять интернет-ресурсом эффективно.

Ключевые слова: интернет-ресурс, контент, информационная система, глобальные информачионные сети, пользовательский интерфейс, юзабилити, эргономика, контент-менеджмент.

\section{A.G. Proaspet}

\section{DEVELOPMENT OF CORPORATE INFORMATION SYSTEM TO MANAGE CONTENT ONLINE RESOURCE OF ENTERPRISE}

Abstract: existing software products for content management of the enterprise Internet resource are difficult for the staff who are responsible for the content management or do not provide the necessary level of security and functionality. According to the author, it is necessary to develop requirements for a corporate information system that allows you to manage Internet resources effectively.

Keywords: Internet resource, content, information system, global information network, user interface, usability, ergonomics, content management.

По данным Федеральной службы государственной статистики, в Московском регионе в производственной сфере $99.8 \%$ организаций используют глобальные информационные сети. В Таблице 1 представлены сведения о доле 
организаций Московского региона, применявших глобальные информационные сети, разграниченные по некоторым видам экономической деятельности в сфере производства.

Таблица 1

Число организаций Московского региона, использовавших глобальные информационные сети, по видам экономической деятельности (в процентах от общего числа обследованных организаций соответствующего вида деятельности)

\begin{tabular}{|l|c|c|c|}
\hline & $\begin{array}{c}\text { Организации, } \\
\text { использовавшие } \\
\text { глобальные } \\
\text { информационные сети }\end{array}$ & $\begin{array}{c}\text { Из них сеть } \\
\text { Интернет }\end{array}$ & $\begin{array}{c}\text { Организации, } \\
\text { имевшие интернет- } \\
\text { ресурс }\end{array}$ \\
\hline $\begin{array}{l}\text { Металлургическое производ- } \\
\text { ство и производство готовых } \\
\text { металлических изделий }\end{array}$ & 100,0 & 100,0 & 83,3 \\
\hline $\begin{array}{l}\text { Производство машин и обору- } \\
\text { дования производство электро- } \\
\text { оборудования, электронного и } \\
\text { оптического оборудования }\end{array}$ & 100,0 & 100,0 & 81,1 \\
\hline $\begin{array}{l}\text { Производство транспортных } \\
\text { средств и оборудования }\end{array}$ & 100,0 & 100,0 & 81,3 \\
\hline
\end{tabular}

Управление контентом - информационным содержимым - интернет-ресурса предприятия осуществляется с использованием специализированного программного обеспечения. Существующие программные продукты, предназначенные для решения такого рода задач, признаны специалистами надёжными и безопасными.

Однако, стоит обратить внимание на следующую проблему: анкетирование сотрудников, не являющихся техническими специалистами, показало, что программные продукты, обладающие, по данным сравнительных анализов, наиболее широкими функциональными возможностями, являются трудными для освоения. Программы обучения, разработанные авторизованными учебными центрами, помогают пользователям овладеть только самыми простыми операциями. По данным опросов слушателей учебных курсов по работе с информационными системами для управления контентом, пользовательский интерфейс наиболее 
распространённых и качественных программных продуктов, решающих данные задачи, не является интуитивно понятным для них. Большинству слушателей не удаётся овладеть навыками грамотного и профессионального контент-менеджмента.

Отсутствие на рынке коммерческого программного обеспечения качественного, безопасного и доступного для освоения пользователям программного продукта для управления контентом интернет-ресурса предприятия делает необходимым разработку такого продукта и требований к нему.

Интернет-ресурс предприятия выполняет следующие задачи:

1. Представление информации о деятельности предприятии.

2. Представление информации о продукции предприятия.

3. Представление информации об истории и структуре предприятия.

4. Привлечение клиентов и партнёров.

5. Приём и обработка заказов.

6. Представление информации об актуальных вакансиях предприятия.

7. Представление информации о достижениях предприятия.

8. Проведение специалистами маркетингового отдела исследований целевой аудитории.

9. Представление актуальной информации о проводимых мероприятиях.

10. Представление актуальной информации об отрасли.

11. Организация электронного документооборота.

12. Получение и обработка почты.

13. Организация рассылок для пользователей и сотрудников.

В связи с необходимостью решения данных задач к интернет-ресурсу предприятия предъявляются следующие требования:

1. Актуальность представляемой информации.

2. Обеспечение круглосуточного и географически независимого доступа к информации.

3. Корректная работа функциональных элементов. 
4. Оптимизированный с точки зрения юзабилити интерфейс, интуитивно понятный пользователям и сотрудникам.

5. Продуманная навигация интернет-ресурса.

6. Быстрый поиск необходимой информации.

7. Оптимально структурированная подача информации.

Программный продукт, с помощью которого контент-менеджер осуществляет управление контентом интернет-ресурса предприятия, должен быть эргономичным инструментом для наполнения и редактирования интернет-ресурсов, соответствующих данным требованиям и выполняющих поставленные задачи. Кроме того, он должен обеспечивать защиту корпоративной информации, позволять оперативно вносить изменения в интернет-ресурс и предусматривать потенциальное расширение функционала в соответствии с нуждами и особенностями конкретного предприятия.

Сотрудники, осуществляющие работу с контентом, должны иметь независимые учётные записи, возможности которых зависят от набора рабочих задач каждого пользователя. Руководители отделов и технические специалисты должны иметь возможность управления уровнями доступа и набором возможностей пользователей.

Программный продукт должен позволять гибкую интеграцию в существующую информационную систему предприятия, иметь возможность учитывать структуру компании и поддерживать работу с большим количеством пользователей разных отделов.

Так как существующие программные продукты обладают достаточно широкими функциональными возможностями, особое внимание при проектировании новой информационной системы следует уделить вопросам юзабилити и эргономики.

\section{Список литературы}

1. ГОСТ 19.201-78 Единая система программной документации (ЕСПД). Техническое задание. Требования к содержанию и оформлению (с Изменением №1). - М.: Изд-во стандартов, 2010. - 3 с. 
2. Круг С. Веб-дизайн: книга Стива Круга или «не заставляйте меня думать!». - СПб.: Символ-Плюс, 2001. - 187 с.

3. Территориальный орган Федеральной службы государственной статистики по г. Москве [Электронный ресурс]. - Режим доступа: http://moscow.gks.ru

\section{References}

1. GOST 19.201-78 unified system of software documentation (the UNIFIED). The terms of reference. Requirements to contents and registration (Change N 1). - M.: Publishing house of standards, 2010. -3 p.

2. Round S. Web design: the book of Steve of the Circle or "don't make me think!". - St. Petersburg: Simvol-PLYUS, 2001. - 187 p.

3. Territorial body of Federal state statistics service in Moscow [Electronic resource]. - Mode of access: http://moscow.gks.ru

Проаспэт Анастасия Георгиевна - бакалавр техн. наук, магистрант ГБОУ ВО Московской области «Технологический университет», Россия, Королев.

Proaspet Anastasiia Georgievna - bachelor of technical sciences, graduate student at SBEI of HE in Moscow region «University of Technology», Russia, Korolyov. 